\title{
8
}
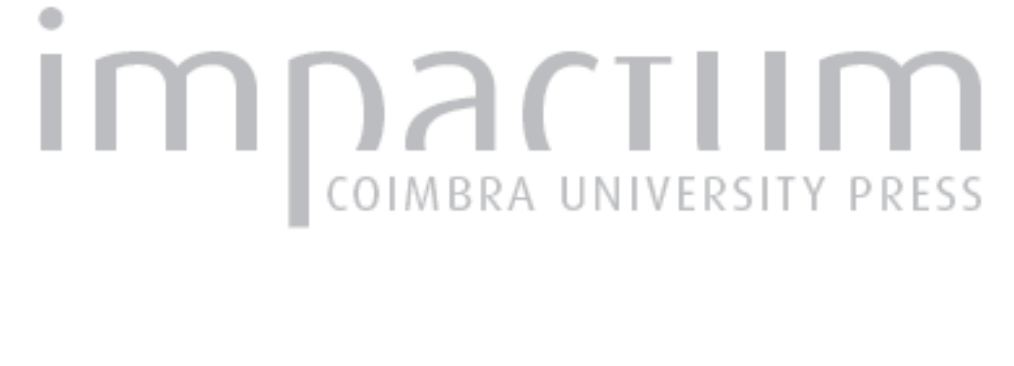

\section{A experiência antepredicativa segundo Husserl passividade e atividade nas constituições originais}

Autor(es): $\quad$ Rosa, Thiago Leite Cabrera Pereira da

Publicado por: Universidade Católica de Petrópolis; Instituto Brasileiro de Informação em Ciência e Tecnologia

URL

persistente:

URI:http://hdl.handle.net/10316.2/33102

DOI: $\quad$ DOl:http://dx.doi.org/10.14195/1984-6754_2_4

Accessed : $\quad$ 26-Apr-2023 11:37:18

A navegação consulta e descarregamento dos títulos inseridos nas Bibliotecas Digitais UC Digitalis, UC Pombalina e UC Impactum, pressupõem a aceitação plena e sem reservas dos Termos e Condições de Uso destas Bibliotecas Digitais, disponíveis em https://digitalis.uc.pt/pt-pt/termos.

Conforme exposto nos referidos Termos e Condições de Uso, o descarregamento de títulos de acesso restrito requer uma licença válida de autorização devendo o utilizador aceder ao(s) documento(s) a partir de um endereço de IP da instituição detentora da supramencionada licença.

Ao utilizador é apenas permitido o descarregamento para uso pessoal, pelo que o emprego do(s) título(s) descarregado(s) para outro fim, designadamente comercial, carece de autorização do respetivo autor ou editor da obra.

Na medida em que todas as obras da UC Digitalis se encontram protegidas pelo Código do Direito de Autor e Direitos Conexos e demais legislação aplicável, toda a cópia, parcial ou total, deste documento, nos casos em que é legalmente admitida, deverá conter ou fazer-se acompanhar por este aviso. 

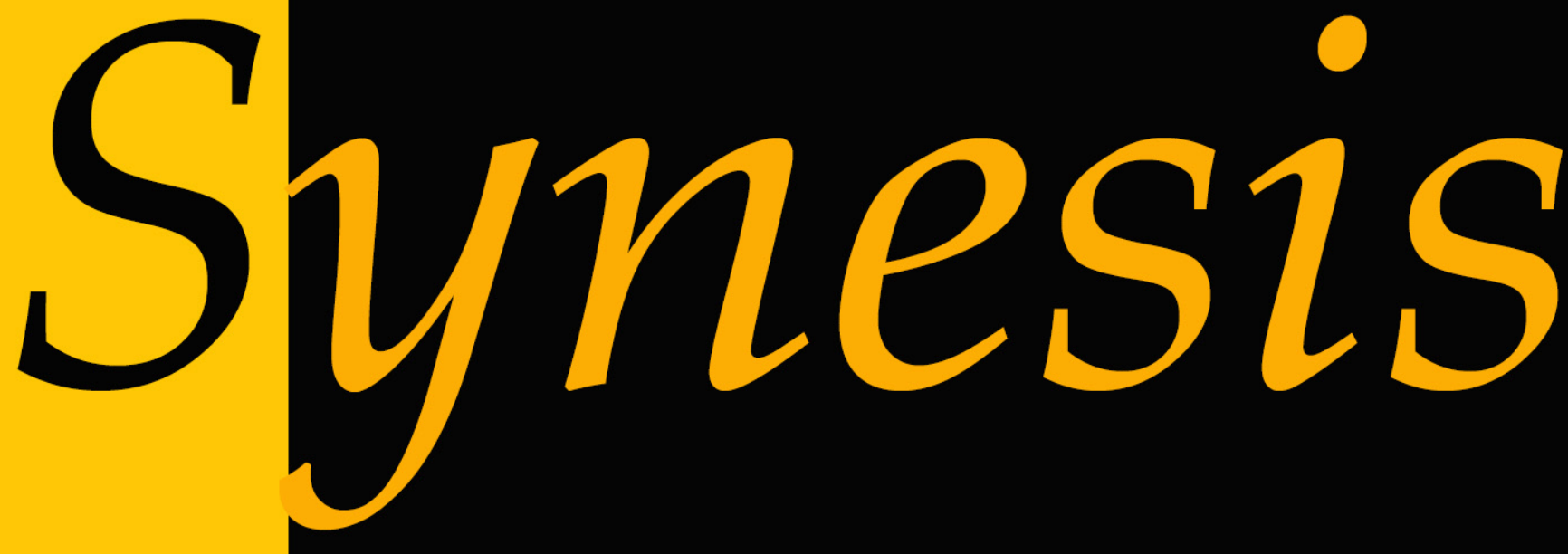

Revista do Centro de Teologia e Humanidades ISSN 1984-6754

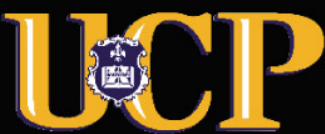




\section{A Experiência Antepredicativa Segundo Husserl PAssividade E ATIVIDADE NAS CONSTITUIÇÕES ORIGINAis}

\section{Thiago Leite Cabrera Pereira da Rosa ${ }^{1}$}

Resumo: A evidência primordial dos objetos na experiência antepredicativa antecede toda cognição e juízo. A fenomenologia de Husserl, dentro do escopo de investigação das bases mais profundas do conhecimento, remete o originar-se de todo objeto à experiência antepredicativa. A descrição da experiência antepredicativa que Husserl propõe em Experiência e Juízo envolve duas distinções fundamentais: por um lado, entre a própria experiência antepredicativa e a predicação; e, por outro, dentro da experiência antepredicativa, entre a passividade e a atividade do eu. Através dessas distinções Husserl dá conta, com a sutileza necessária, da fluidez de nossa consciência em sua variação de objetos, da nossa distinção natural entre subjetivo e objetivo, e da irredutibilidade da experiência à predicação.

Palavras-chave: Percepção, Objeto, Predicação, Experiência Antepredicativa.

Abstract: The primordial evidence of objects in the antepredicative experience precede all cognition and judgement. The phenomenology of Husserl, persuing his investigation into the deepest foundations of knowledge, refers the origin of any object to the antepredicative experience. The description of the antepredicative experience that Husserl presents in Experience and Judgement involves both fundamental distinctions: the distinction between the predication and antepredicative experience itself, and the distinction, internal to the antepredicative experience, between the passivity and the activity of the self. Through these distinctions Husserl explains, with the subtlety required, the flow of our consciousness in its range of objects; our natural distinction between subjective and objective; and the irreducibility of experience to predication.

1 Graduado em Filosofia pela UFRJ. Mestrando em Filosofia pela Universidade Federal do Rio de Janeiro (PPGF-UFRJ).

http://www.ucp.br/html/joomlaBR/synesis/synesis.htm 
Keywords: Perception, Object, Predication, Antepredicative experience.

\section{Introdução}

Dentro do escopo de investigação das bases mais profundas do conhecimento, esclarecer o originar-se de todo objeto na experiência antepredicativa, onde há um misto de passividade e atividade de consciência, constitui-se em tarefa fundamental para a fenomenologia de Husserl. É preciso descrever o surgimento à consciência na percepção de pré-objetos originais, pois esses fundamentariam, por sua autoevidência, a verdade dos juízos e do conhecimento, segundo a concepção husserliana. Pela abordagem profunda e detalhada, à altura da importância e complexidade das questões envolvidas, as reflexões que Husserl, ciente da exigência do problema, promoveu em seus últimos escritos sobre o tema requerem uma atenta e cuidadosa avaliação.

A noção de objeto é fundamental na fenomenologia de Husserl. Objeto para Husserl, em sentido pregnante, é o substrato de um juízo, ou, na definição mais corrente, é todo sujeito de predicações possíveis. E se a origem de todo objeto está na experiência antepredicativa, todo juízo estará fundado em última instância nela.

Em Experiência e Juizo, uma de suas últimas obras ${ }^{2}$, o âmbito da experiência antepredicativa recebe atenção especial do filósofo, que lhe dedica toda a primeira parte do livro. Com foco concentrado nessa obra essencial, o presente escrito examinará e avaliará as últimas posições de Husserl a respeito da relação genealógica dos objetos com a experiência antepredicativa, âmbito no qual, em última instância todo objeto teria gênese, através de constituições passivas e ativas. Tematizaremos a descrição que Husserl faz de como o objeto é formado na experiência antepredicativa (ou pré-predicativa) com interesse em procurar esclarecer dois pontos: $\left(1^{\circ}\right)$ Por que Husserl defende que o objeto é formado num âmbito antepredicativo e não

2 A publicação é póstuma e a redação final da obra pertence a Ludwig Landgrebe, que fora antigo assistente de Husserl.

http://www.ucp.br/html/joomlaBR/synesis/synesis.htm 
predicativo? $\left(2^{\circ}\right)$ Por que Husserl defende que essa experiência antepredicativa é um misto de passividade e atividade do eu?

Para tanto dividiremos a exposição em mais duas partes: na primeira, procuraremos dar conta sinteticamente da descrição $0^{3}$ feita por Husserl da experiência antepredicativa. $\mathrm{Na}$ segunda, trataremos de comentar criticamente essa descrição, tendo como fio condutor as questões assinaladas, que versam basicamente sobre a validade de duas distinções fundamentais feitas por Husserl ao longo de sua exposição: entre experiência antepredicativa e predicação; e entre passividade e atividade na experiência antepredicativa.

\section{A descrição husserliana da experiência antepredicativa ${ }^{4}$ \\ 1.1 Simples apreensão}

O conteúdo e a verdade do conhecimento predicativo estão fundados, respectivamente, na originalidade e na auto-evidência antepredicativa. Todo sentido e todo objeto têm por base alguma experiência antepredicativa, ou seja, alguma experiência perceptiva, que dá, originalmente e em auto-evidência, sentidos e objetos. Forçando a genética ainda mais a fundo, descobre-se, por fim, que originalidade e evidência derivam primordialmente de uma dimensão passiva da percepção.

Não que na consciência intencional perceptiva haja pura passividade, pois subjaz a toda percepção uma operação constituidora de objetos que envolve a atividade do eu. Reconhece-se, no entanto, um âmbito de passividade, que é préconsciente. Nele há constituição por meio de síntese passiva.

A constituição antepredicativa, realizada por meio da síntese de perfis, parte

3 Como é possível descrever um âmbito tão originário? Segundo os princípios da fenomenologia é preciso, mais que tudo, descrever sem construir, sem formular teorias e hipóteses. Em Experiênica e Juízo Husserl faz escassas observações metodológicas. O esboço maior que chega a formular seria o do método da "consideração abstrata": convertemos as dadidades sensíveis, ou derivados análogos a elas, em objeto temático. O exemplo dado por Husserl é o branco de uma superfície que vemos daquele ângulo determinado naquele instante determinado. Esse branco, que não era objeto da minha percepção, mas algo apreendido na apercepção, algo por meio do qual a consciência constituiu o objeto, torna-se um objeto de uma percepção "abstrata", através da qual posso me dar conta da atividade sintética anteriormente realizada.

4 A quem se interesse por conferir passagens específicas, vale notar que a divisão do texto de Husserl em parágrafos indica com clareza onde cada parte do conteúdo aqui descrito é tematizada.

http://www.ucp.br/html/joomlaBR/synesis/synesis.htm 
de sensações e tem por produto objetos particulares, enquanto que a constituição que envolve a síntese categorial parte de objetos e tem por produto objetos considerados conjuntamente, sejam ou não estados de coisas. Como objetos são ou particulares ou constituídos, em última instância, a partir de particulares, verifica-se que o plano antepredicativo funda o categorial.

Tomada como um todo, como acabamos de comentar, a experiência antepredicativa constitui particulares a partir de sensações, que são dados imanentes à consciência, vivências das quais não se tem experiência. Entretanto, para que se aprofunde a compreensão da constituição antepredicativa, é preciso que sejam considerados abstratamente os diferentes níveis em que ela se dá, o que significa distinguir nela uma série de tipos de síntese, especialmente quanto à atividade e à passividade.

Passiva, a síntese interna do tempo, que o nível mais fundamental da experiência antepredicativa, estabelece a coexistência e a sucessão das sensações. Já a síntese associativa, que se encontra no nível imediatamente superior ao da síntese interna do tempo, sendo ainda passiva, estabelece relevos de homogeneidade e heterogeneidade entre as sensações, constituindo semelhanças, diferenças, igualdades, singularidades, grupos ou mesmo campos sensoriais. Os relevos são destacamentos associativos constituídos a partir de sensações ordenadas pela síntese interna do tempo. Os relevos de homogeneidade são produtos de fusões associativas, os relevos de heterogeneidade são produtos de contrastes associativos.

Por ter força afetiva, o relevo, ou destacamento, exerce um estímulo (Reiz) sobre o eu. Tal estímulo é condição necessária, mas não suficiente, para o voltar-se do eu ao relevo. Porém, quanto maior a intensidade da força afetiva do relevo, maior o estímulo exercido sobre o eu e maior sua tendência a voltar-se para o relevo.

Correlato da força afetiva do relevo, o estímulo sofrido provoca a tendência do eu a voltar-se ao relevo. Pode-se chamar 'tendência' também o próprio voltarse do eu ao relevo, em obediência ao estímulo. A tendência, nessa acepção, já caracteriza a atividade do eu em atos dóxicos como a percepção. A visada de relevos se dá segundo um sentido, um tipo, pelo qual os relevos são sintetizados em perfis. 
A esse terceiro nível sintético da experiência antepredicativa segue um último, em que, pela síntese de perfis, enquanto modos de aparecer de um mesmo, constitui-se o objeto com contornos definidos.

O interesse perceptivo, primariamente involuntário, se desenvolve ao longo do processo como um esforço por enriquecer a visada do objeto, abarcando sempre novos perfis, isto é, novos modos de aparecer daquele mesmo (objeto) dentro de um horizonte intencional de sentido.

A distinção entre as dimensões passiva e ativa da percepção se mostra necessária para dar conta, por exemplo, do fato de que não se pode determinar voluntariamente o conteúdo de uma imagem perceptiva (a qüididade um perfil), mas apenas se ela se dá ou não. Posso, por exemplo, fechar os olhos, de modo que não apareçam imagens visuais, isto é nenhum perfil de objetos visuais, mas não posso escolher o teor do que aparecerá a partir do momento que abra os olhos.

Cada tendência desperta um horizonte intencional (de interesse e esforço) que aponta sempre para além de si de um modo vazio, requerendo o preenchimento ao longo do processo perceptivo. Toda intenção é, desse modo, carregada de expectativas quanto à quididade do objeto, que expectativas que virão a ser negadas, modificadas, ou confirmadas com maiores determinações ${ }^{5}$.

Assim, a percepção abarca não só um âmbito primordial de passividade, mas também um conjunto de processos, ao mesmo tempo sintéticos e dóxicos, realizados pelo eu. Cada um desses processos pode ser dividido em fases, mas se define fundamentalmente por uma unidade sintética que visa um objeto intencional e que é desencadeada, como vimos, a partir de uma tendência do eu.

Para efeito de comparação com a imaginação ou com a memória, notese que a tendência perceptiva caracteriza-se por ser sempre acompanhada pelo interesse no objeto como existente e presente diante do eu, pelo que o eu é levado a ter uma crença na existência do objeto da percepção. Tal modo de interesse, porém,

$5 \quad$ Cf. HUSSERL, Edmund. Esperienza e giudizio. Inclui o texto alemão original, com tradução italiana de Filippo Costa e Leonardo Samonà. Milano: Bompiani, 2007, § 21.

http://www.ucp.br/html/joomlaBR/synesis/synesis.htm 
é explicado pela corporeidade (leibhaftig) ${ }^{6}$ e originalidade do objeto visado, o que remete a determinação do caráter tético, ou modo de posição do objeto ao âmbito passivo.

\subsection{Desdobramentos: explicação (Explikation) e a contemplação}

\section{relacional}

Até o momento, tocamos apenas em aspectos mais gerais da apreensão perceptiva antepredicativa. No entanto, para que se consiga entender a fundação da predicação na experiência antepredicativa, faz-se necessário um detalhamento de algumas espécies de apreensões perceptivas. A explicação funda a distinção entre predicados simples e sujeito gramatical, já a contemplação relacional funda os predicados relativos.

A simples apreensão estabelece o objeto enquanto unidade sintética indeterminada, um mesmo ser em diversas aparências. Já ativa, seu desenvolvimento busca mais lados do objeto, isto é, procura contemplar a totalidade do objeto, mas sempre como unidade, como um mesmo, um todo. A expectativa delineada na simples apreensão do objeto se caracteriza pela consciência da espaço-temporalidade do objeto, enquanto objeto real, pela consciência de uma certa familiaridade do objeto e pela consciência de um conjunto de possibilidades de determinação do objeto. A contemplação explicativa envereda pelo horizonte delineado na simples apreensão, buscando conhecer mais aspectos particulares do objeto, suas partes, conexões e determinações internas. A primeira é o nível básico inescapável de toda percepção, pois é condição necessária da segunda.

A explicação "é a direção do interesse do interesse percetivo que acede ao

$6 \quad$ A esse respeito, dão bom testemunho intérpretes como J. Brough e E. Tugendhat. O primeiro escreve: “(..) o que distingue a percepção de atos de representação que compartilham uma parte ou mesmo a totalidade dessas características? A resposta de Husserl é a de que a percepção não apenas dá o objeto como presente e existente, mas dá o objeto em pessoa (leibhaftig) (...)" (Introdução de HUSSERL, E. Phantasy, Image consciousness, and Memory. Dordrecht (The Netherlands): Springer, 2005, p. XXXIV.) e o segundo “(...) Husserl chama (...) a auto-dadidade (Selbstgegebenheit) da percepção, para distingui-la da fantasia, de corporal (leibhaftig) ou original (Idéias 126)" (TUGENDHAT, E. Der Wahrheitsbegriff bei Husserl und Heidegger. Berlin: Walter de Gruyter, 1970, p. 167.). 
horizonte interno do objeto" "Visa desdobrar tudo o que o objeto é, todas as suas determinações, sua qüididade, seguindo as expectativas do interesse (prescrições de sentido do horizonte). No entanto, é impossível explicar, percorrer, todos os perfis de um objeto espaço-temporal.

Na explicação, dá-se a auto-evidência da distinção entre objeto-substrato e determinação. Por isso, encontra-se nela a origem da distinção das categorias lógicas básicas, sujeito e predicado. Se, na simples apreensão, o objeto é visado em sua totalidade geral e indeterminada, por meio de expectativa que define o horizonte de interesse da apreensão, na explicação, há o preenchimento do interesse cognitivo por um processo progressivo de determinação do objeto em suas particularidades. Tal processo se desenvolve como uma série interligada de apreensões cujas objetualidades se sobrepõem e um tipo especial de síntese de identidade, na qual apreende-se $X$ como substrato e $y, z$, etc como suas determinações, sendo esta distinção do modo de apreensão auto-evidente. Vê-se aqui novamente a importância genética da percepção antepredicativa para a experiência predicativa.

A explicação pode ser ramificada, pois uma determinação pode assumir a função de um substrato de explicações adicionais, tornando-se subtema da intenção ou mesmo tema, no caso de abandono do tema original pela atenção.

Além da explicação, há ainda, como já assinalamos, mais um importante tipo de apreensão perceptiva, a contemplação relacional, que busca alcançar as determinações externas do objeto, isto é, as suas determinações relativas (a outros objetos co-presentes campo perceptivo).

A consciência de uma coleção de objetos, isto é, de vários objetos, é condição necessária, mas não suficiente para a apreensão de uma relação entre esses objetos. Para que da simples contemplação de alguns objetos se evolua à apreensão de uma relação, é necessário um interesse de tipo especial. Por seleção desse interesse, a contemplação se dirige a um dos objetos como tema principal e aos outros como temas relativos. Assim, são apreendidas determinações do objeto

7 HUSSERL, Edmund. Esperienza e giudizio. Inclui o texto alemão original, com tradução italiana de Filippo Costa e Leonardo Samonà. Milano: Bompiani, 2007, § 22, p. 240.

http://www.ucp.br/html/joomlaBR/synesis/synesis.htm 
principal relativas aos objetos secundários, determinações antepredicativas como, por exemplo, "maior que Maria", sendo Maria, no caso, o tema relativo. Como a contemplação relacional visa objetos independentes do ponto de vista da apreensão, não há, a priori, precedência de um objeto sobre outro quanto a ser tema principal.

\section{Fundamentação das distinções capitais na descrição husserliana}

\subsection{Experiência antepredicativa e predicação}

Pela descrição da experiência antepredicativa, e, especialmente, pela descrição do que Husserl chama de explicação, talvez possa parecer estranho para muitos que a percepção não seja já predicativa, na medida em que já há visada de determinações de um objeto. No entanto, ver determinação $\mathrm{p}$ de $\mathrm{S}$ (ex. ver o branco do cavalo) é diferente de ver que $\mathrm{S}$ é p (ver que o cavalo é branco), pois ver $\mathrm{S}$ e ver $\mathrm{p}$ de $\mathrm{S}$ (ver cavalo e ver branco do cavalo) são condições necessárias mas não suficientes de ver que $\mathrm{S}$ é $\mathrm{p}$ (ver que o cavalo é branco).

Husserl é enfático em assinalar que da explicação para a predicação, há uma mudança de atitude: na explicação o objeto-substrato $S$ era retido passivamente enquanto sua determinação $p$ era apreendida, tendo como resultado marginal uma coincidência passiva entre $S$ e $p$; já na predicação é justamente essa coincidência que é apreendida ativamente, que é visada tematicamente. A atividade predicativa visa ao mesmo tempo, através de "dois raios", $S$ e $p$ e o elo entre ambos, e o interesse está voltado para o acréscimo de sentido que a determinação $p$ dá ao objeto-substrato $S$. Como realização desse interesse uma síntese ativa de segunda ordem produz a consciência de que "S é p". Na formulação de Husserl: a predicação é "a realização ativa da unidade de identidade entre $S$ e $p "{ }^{8}{ }^{8}$ De fato, segundo Husserl,

para que o substrato da explicação se torne um sujeito e para que os explicados se tornem predicados, é necessário que a visada se volte para a unidade que é passivamente pré-constituída dentro da atividade receptiva do processo de explicação [...]

$8 \quad$ Id. Ibid. $\S 50$, p. 498.

http://www.ucp.br/htmlljoomlaBR/synesis/synesis.htm 
Na predicação fala-se, portanto, em um nível superior de atividade do eu:

Não mantemos mais uma explicação meramente contemplativa, mas uma atividade de identificação predicativa, e essa é uma consciência apreendedora, cuja atividade não por um único raio, mas por muitos raios (uma atitividade politética). [...] $\mathrm{Na}$ atividade da explicação, o objeto está já implicitamente "determinado" como p, isto é, ele é clarificado e feito explícito enquanto tal, mas o "ser-determinadocomo" não é apreendido. ${ }^{9}$

Em um segundo aspecto, é fundamental para Husserl esclarecer que a experiência não é primariamente discursiva, conceitual. A discursividade e a conceitualização não dão conta do todo da experiência. Na verdade, a experiência é a base da discursividade e não se reduz a ela. A experiência sempre dá algo indeterminado para além dos juízos formulados e formuláveis, algo do nível das simples dadidades que não pode ser totalmente descrito, algo que escapa à universalidade do conceito. Tanto que novos juízos sempre podem ser produzidos, ao infinito, no exemplo mais óbvio, novas comparações, novas contemplações relacionais. A experiência é fonte, condição necessária, e dá matéria a inesgotáveis juízos possíveis.

\subsection{Passividade e atividade na experiência antepredicativa}

Em um primeiro aspecto, se faz necessário distinguir uma visada de fundo (covisada), sem foco, indeterminada, sem contornos, isto é, uma contemplação meramente passiva, e uma visada atenta, temática, com contornos, ou seja, uma contemplação ativa. No entanto, é preciso compreender que um nível não é totalmente separável do outro, pois ambos coexistem desde sempre na contínua dinâmica do desvio de interesse e atenção da experiência cotidiana, e o âmbito ativo depende do passivo, em outras palavras, é preciso uma pré-visada passiva para que se possa direcionar a atenção a um objeto. Conforme o próprio Husserl assinala,

sob o termo "percepção", por exemplo, distinguimos, por um lado,

$9 \quad$ Id. Ibid. $\S 50$, p. 500.

http://www.ucp.br/html/joomlaBR/synesis/synesis.htm 
o simples ter em consciência das aparições originais (aquelas que apresentam objetos em sua corporeidade original). Desse modo, um campo inteiro de percepção se estabelece para nós - já na pura passividade. Por outro lado, recai sob o termo "percepção", a percepção ativa, apreensão ativa de objetos que se destacam em um campo perceptivo que os contém. ${ }^{10}$

Por outro lado, ao distinguir, na experiência antepredicativa, um domínio de passividade e um domínio de atividade, Husserl procura mostrar a origem das noções de objetividade e subjetividade mobilizadas na compreensão da experiência pela atitude natural, ou, como quer a filosofia analítica, a origem do uso das expressões "objetivo" e "subjetivo" na linguagem ordinária para caracterizar aspectos distintos da experiência cotidiana.

O objeto não é meramente subjetivo, pois seu conteúdo funda-se no que é pré-dado à atividade do eu. Mas o objeto também não é apenas objetivo, pois ele é constituído intencionalmente pela atividade do ego, que envolve o voltar-se para o pré-dado, sua simples apreensão e, em seguida, a explicação e a contemplação relacional.

Quando eu viso algo na percepção, viso este algo como existente, como pertencente ao mundo, ou seja, já existente antes da visada, como existente independentemente da minha visada, da minha atenção e interesse. ${ }^{11} \mathrm{Na}$ atitude natural, digo que essa coisa visada é objetiva, real. Esse modo de visar se dá justamente por conta da origem da percepção estar no âmbito da pré-dadidade passiva, no âmbito de algo para o qual o eu não está voltado.

A subjetividade do objeto, isto é, seu estar presente à consciência e o aspecto pelo qual ele é visado, tem origem na dimensão ativa da experiência antepredicativa, com suas respectivas intenções do ego.

Cabe aqui fazer distinção entre unidade subjetiva e unidade objetiva. A unidade objetiva é demonstrada pelo fato de que um mesmo objeto pode ser visado

\footnotetext{
$10 \quad$ Id. Ibid., $\S 17$, p. 176 e 178.

11 Cf. Id. Ibid., $\S 7$, p. 58 e 60.
}

http://www.ucp.br/html/joomlaBR/synesis/synesis.htm 
ao mesmo tempo por diversas consciências. E a unidade subjetiva, pelo fato de que uma mesma consciência pode visar diversos objetos ao mesmo tempo. Há uma unidade intencional subjacente ao fato de uma percepção, uma memória e uma imaginação serem minhas. Porém, subjacente ao fato de um mesmo objeto, um lápis, por exemplo, ser visado várias vezes ou por várias pessoas há uma unidade objetiva, que remonta à unidade constituída passivamente tanto pela síntese passiva do tempo e quanto pelas sínteses de associação. A forma fundamental de unidade de todo objeto percebido é sua posição no tempo objetivo, cuja origem é puramente passiva.

Por outro lado, se a percepção fosse pura passividade, não haveria interesse e atenção. Se fosse pura atividade, não se poderia vir a visar outro objeto, pois não haveria nada para além do que se tem consciência, ou seja, o que se está visando agora. Só a distinção dessas duas dimensões explica satisfatoriamente como o fluxo de consciência de um ego se alterna entre objetos sucessivos de interesse. Não há consciência sem interesse e atividade, mas não há possibilidade de variação de interesse sem algo, pré-dado e co-visado de que ainda não se tem consciência, a que a visada se possa se aplicar. Quando a atenção e o interesse perceptivo se desviam de um tema, este cai no fundo passivo, continuando, não obstante, a ser apreendido. Ser co-visado dessa maneira, isto é, ser apreendido nesse fundo passivo, é o que permite que ele possa voltar a ser visado tematicamente no futuro.

Nos processos perceptivos, além do interesse, da atenção e da atividade de apreensão, em seus diversos modos, há também atividade subjacente nas intenções de antecipação (que podem inclusive sofrer frustração) e, mais fundamentalmente, no mero voltar-se do eu em direção ao objeto.

No nível mais basal da percepção propriamente dita (percepção ativa) já percebemos o objeto como múltiplas manifestações de um mesmo e isso só pode ser produzido, realizado por uma síntese ativa. Temos acesso a múltiplos e os consideramos manifestações de um mesmo. Os múltiplos em si não nos dizem que são o mesmo objeto. Essa havia sido a crítica básica de Hume à noção realista de substância defendida pela metafísica tradicional, mas sua solução fora o ceticismo em relação a substâncias, passando a admitir, em sua ontologia, apenas impressões e 
idéias. Para Husserl, há atividade do eu, mas essa é determinada passivamente pelo que é pré-dado (as pré-dadidades como que instruem e corrigem os desempenhos ativos do eu). A distinção entre as dimensões passiva e ativa da percepção se mostra necessária para explicar, por exemplo, o fato corriqueiro de que não se pode determinar voluntariamente o conteúdo de uma imagem perceptiva (isto é, a qüididade de um perfil, que é bastante determinada passivamente, função muito mais da pré-dadidade do que do voltar-se do eu), mas apenas se essa imagem se dá ou não (posso, por exemplo, fechar os olhos, de modo que não apareçam imagens visuais, isto é nenhum perfil de objetos visuais).

Por fim, a dimensão passiva da experiência antepredicativa é que determina a corporeidade e originalidade em o objeto nela se dá. Esses dois traços do objeto da percepção dão o caráter de certeza que nega as intenções antecipadoras contrárias (o sentido da série de aparências pode ser modalmente modificado por conta dela) e que fundamenta a verdade dos juízos.

\section{Conclusão}

A evidência primordial dos objetos na experiência antepredicativa antecede toda cognição e juízo. Antes de despertar interesse e atenção cognitiva e predicativa, o objeto está presente no campo de consciência enquanto provoca estímulos, afecções no eu. Nas palavras de Husserl:

Falar de evidência, de dadidade evidente, não significa aqui outra coisa que auto-dadidade, a maneira como um objeto em sua dadidade pode ser caracterizado como "em pessoa aí" ["selbst da"], "corporealmente aí" ["leibhaft da"], em oposição à sua mera representação [Vergegenwärtigung], a vazia, apresentação meramente indicativa dele. ${ }^{12}$

A qüididade dos objetos tem origem passiva e, por isso, é objetiva, e

$\overline{12 \quad \text { Id. Ibid. } \S} 4$, p. 33-34.

http://www.ucp.br/htmlljoomlaBR/synesis/synesis.htm 
garante a verdade do conhecimento. O conteúdo das dadidades passivas é que funda a qüididade dos objetos apreendidos.

Assim, para esclarecer nossos desempenhos cotidianos de experiência e juízo, bem como nossas noções da atitude natural, reconheceu-se a necessidade da distinção fenomenológica entre experiência antepredicativa e predicação e, dentro da experiência predicativa, entre atividade e passividade. Através dessas distinções Husserl dá conta, com a sofisticação necessária, da fluidez de nossa consciência em sua variação de objetos, da nossa distinção natural entre subjetivo e objetivo, e da irredutibilidade da experiência à predicação. 


\section{Referências Bibliográficas}

\section{Fontes primárias:}

HUSSERL, Edmund. Esperienza e giudizio. Inclui o texto alemão original, com tradução italiana de Filippo Costa e Leonardo Samonà. Milano: Bompiani, 2007.

. Experience and judgment: Investigations in a genealogy of Logic. Tradução de James S. Churchill e Karl Americks. London: Routledge \& Kegan Paul, 1973.

Idées directrices pour une phénomenologie. Tradução de Paul Ricœur. Paris: Gallimard, 2005.

. Investigações Lógicas. v. I e II. Tradução de Diogo Ferrer (v.

I), Pedro M. S. Alves (v. II, t.I) e Carlos Aurélio Morujão (v. II, t. I e II). Lisboa: Centro de Filosofia da Universidade de Lisboa, 2005 (v. I) e 2007 (v.II).

La crise des sciences européennes et la phénoménologie transcendentale. Tradução e prefácio de Gerard Granel. Paris: Gallimard, 2004. Méditations cartésiennes: introduction à la phénoménologie. Traduição de Gabrielle Peiffer e Emmanuel Lévinas. Paris: Librairie Philosophique J. Vrin, 2001.

1. Phantasy, Image Consciousness, and Memory. Tradução de J. Brough. Dordrecht: Springer, 2005.

\section{Fontes secundárias:}

CAIRNS, Dorion. Guide for Translating Husserl. Phaenomenologica, Haia, n. 55, 
1973.

LANDGREBE, Ludwig. The problem of passive constitution. Tradução de Donn Wellan. In: Analecta Husserliana. Dordrecht: Martinus Nijhoff, 1978, p. 23-36.

LARRABEE, Mary Jeanne. Husserl's static and genetic phenomenology. Man and World 9, n. 2, 1976, p. 163-174.

MILLER, Izchak. Husserl, Perception, and Temporal Awareness. Cambridge: MIT Press/Bradford Books, 1984.

MOHANTY, J. N. The 'Object' in Husserl's Phenomenology. Philosophy and Phenomenological Research, Providence (U.S.), v. 14, n. 3, mar. 1954.

SMITH, Barry; SMITH, David W (Ed.). The Cambridge Companion to Husserl. Cambridge \& New York: Cambridge University Press, 1995.

SOKOLOWSKI, Robert. The Formation of Husserl's Concept of Constitution. Haia: Martinus Nijhoff, 1964.

Husserlian Meditations: How Words Present Things.

Evanston: Northwestern University Press, 1974.

Immanent Constitution in Husserl's Lectures on Time.

Philosophy and Phenomenological Research, Providence (U.S.), Vol. 24, No. 4 (Jun., 1964).

TUGENDHAT, Ernst. Der Wahrheitsproblem bei Husserl und Heidegger. Berlin: Walter de Gruyter, 1970. 